Silvana V. Goellner, Sebastião J. Votre, Lazer e Gênero nos Programas de Esporte e Lazer das Cidades Ludmila Mourão e Márcia Luiza M. Figueira

\title{
LAZER E GÊNERO NOS PROGRAMAS DE ESPORTE E LAZER DAS CIDADES
}

Recebidoem: $13 / 07 / 2009$

Aceito em: 20/04/2010

\author{
Silvana Vilodre Goellner ${ }^{1}$ \\ Universidade Federal do Rio Grande do Sul (UFRGS) \\ Porto Alegre - RS - Brasil \\ Sebastião Josué Votre ${ }^{2}$ \\ Ludmila Mourão ${ }^{3}$ \\ Universidade Gama Filho (UGF) \\ Rio de Janeiro - RJ - Brasil \\ Márcia Luiza Machado Figueira ${ }^{4}$ \\ Universidade Federal do Rio Grande do Sul (UFRGS) \\ Porto Alegre - RS - Brasil
}

RESUMO: Este artigo aborda desigualdades de gênero no acesso às políticas públicas que venham ao encontro de necessidades humanas. O objetivo geral é analisar bases de dados de estudos desenvolvidos em Porto Alegre e no Rio de Janeiro, em núcleos do Programa Esporte e Lazer na Cidade. A partir dessa análise, identificamos desigualdades nas oportunidades de acesso e permanência de mulheres nos núcleos e interpretamos os principais desafios que as propostas de integração devem enfrentar, para cumprirem as metas de inclusão. Os resultados apontam para impedimentos culturais e de divisão do trabalho e do lazer, para que mulheres e homens possam ter acesso às mesmas oportunidades de lazer.

PALAVRAS-CHAVE: Identidade de Gênero. Centros de Convivência e Lazer. Políticas Públicas.

1 Doutora em Educação pela UNICAMP. Professora Associada da Escola de Educação Física da Universidade Federal do Rio Grande do Sul. Coordenadora do GRECCO (Grupo de Estudos sobre Cultura e Corpo) e do CEME (Centro de Memória do Esporte - ESEF/UFRGS) Pesquisadora Produtividade Pesquisa CNPq.

2 Pós-doutorado em História do Esporte pela Universidade de Strath-Clyde, Glasgow, Escócia. Doutor pela PUC-RJ; Livre-docente pela UFRJ; Professor do Programa de Pós-Graduação em Educação Física da Universidade Gama Filho. Pesquisador Produtividade Pesquisa CNPq.

3 Doutora em Educação Física da Universidade Gama Filho. Coordenadora e Professora do Programa de Pós-Graduação em Educação Física da Universidade Gama Filho.

4 Mestre e Doutora em Ciências do Movimento Humano (UFRGS). Professora da Rede Municipal de Ensino de Porto Alegre. Pesquisadora do Centro de Memória do Esporte (ESEF-UFRGS) e do GRECCO (Grupo de Estudos sobre Cultura e Corpo). 
Silvana V. Goellner, Sebastião J. Votre, Lazer e Gênero nos Programas de Esporte e Lazer das Cidades Ludmila Mourão e Márcia Luiza M. Figueira

\section{LEISURE AND GENDER IN SPORTING AND LEISURE PROGRAMS IN THE CITIES}

ABSTRACT: This paper addresses inequalities of gender in accessing public policies related do human needs. The general goal is to analyze data bases of researches developed in the cities of Porto Alegre and Rio de Janeiro, in centers of the Program Sport and Leisure in the City. Departing from these analyses, we have identified inequalities in opportunities given to women to have access to and to remain in leisure centers and interpret the main challenges proposals of integration have to deal with, in order to give account of their goals of inclusion. Results point to cultural barriers, as well as barriers related to division of labor and leisure, for women and men to have access to the same opportunities of leisure.

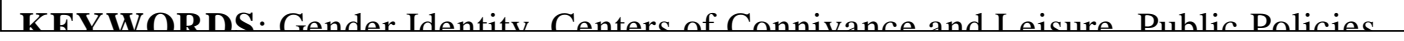

\section{Introdução}

$\mathrm{Na}$ agenda dos projetos sociais que oferecem práticas corporais e esportivas, a melhoria da saúde, o acesso aos equipamentos e as atividades de lazer figuram como metas a serem almejadas pelos seus usuários e usuárias. Considerando que a desigualdade social é uma realidade (IBGE, 2000), postulamos que este estudo possa colaborar para identificar grupos que têm sido menos favorecidos no acesso aos serviços públicos de esporte e lazer e as propostas decorrentes são úteis no aprimoramento das políticas públicas voltadas para a inclusão dos segmentos marginalizados.

A desigualdade de oportunidade nas relações de gênero é uma questão que, muitas vezes, não aparece contemplada na proposição de políticas públicas voltadas para o esporte e o lazer no Brasil. Este estudo identifica e discute diferenças de oportunidades de lazer para homens e mulheres em programas públicos de esporte e lazer nas cidades de Porto Alegre e Rio de Janeiro. Numa perspectiva crítica, propomonos contribuir para uma melhor compreensão das características, dos desafios e das alternativas para superá-los. 
Silvana V. Goellner, Sebastião J. Votre, Lazer e Gênero nos Programas de Esporte e Lazer das Cidades Ludmila Mourão e Márcia Luiza M. Figueira

Partimos do pressuposto de que o lazer, como as demais práticas humanas, é um espaço generificado e generificador, em que se produzem e reproduzem representações de feminilidade e masculinidade (GOELLNER et al, 2009). Postulamos também que, em torno dessas representações, ocorrem gestos de protagonismo e travam-se embates por significação, reconhecimento e visibilidade.

A questão de gênero sobressai, no contexto dos projetos sociais, pela força com que interfere na adesão e permanência de homens e mulheres nas atividades de lazer e pelos desafios e demandas que provoca. O presente estudo identifica e analisa parte desses desafios, a partir de bases de dados de outras pesquisas, mais amplas, intituladas "Políticas de Promoção da Saúde na Gestão do Lazer em Porto Alegre" e "Discriminação de idade, gênero, pessoas com deficiência e raça em programas de esporte e lazer na cidade do Rio de Janeiro: subsídios para elaboração de políticas inclusivas $"$ ".

A escolha de gênero como marcador social se justifica, entre outras razões, porque na literatura específica de programas de promoção do lazer e da atividade física tem sido destacado que o índice de sedentarismo entre as mulheres é bastante significativo, o que demandaria estratégias de intervenção voltadas para o público feminino. De acordo com dados levantados no Brasil em 2002, pelo Centro de Estudos do Laboratório de Aptidão Física de São Caetano do Sul (CELAFISCS), entidade responsável pela coordenação de um dos programas de promoção da saúde mais

\footnotetext{
5 Pesquisa desenvolvida pelo Núcleo da Escola de Educação Física da Universidade Federal do Rio Grande do Sul da Rede CEDES (Centro de Desenvolvimento do Esporte Recreativo e do Lazer) com apoio financeiro da Secretaria Nacional de Desenvolvimento de Esporte e Lazer do Ministério do Esporte. ${ }^{6}$ Pesquisa desenvolvida pelo Grupo de Estudos Semiótica da Atividade Humana, com apoio financeiro da FAPERJ.
} 
Silvana V. Goellner, Sebastião J. Votre, Lazer e Gênero nos Programas de Esporte e Lazer das Cidades Ludmila Mourão e Márcia Luiza M. Figueira

destacados do país, o Agita São Paulo ${ }^{7}, 70 \%$ dos sedentários de todo o país são mulheres, tendência esta que tem levado a considerar a mulher como um grupo de risco. $\mathrm{Na}$ literatura, detectamos uma lacuna na análise e interpretação dos vieses na distribuição de homens e mulheres nas atividades de lazer ${ }^{8}$. Este estudo representa pequeno gesto no sentido de explorar essa lacuna.

O objetivo deste artigo é analisar relatórios de estudos sobre gênero no lazer ativo, nas cidades de Porto Alegre e do Rio de Janeiro, a fim de identificar as razões do viés de distribuição dos participantes por gênero e as razões pelas quais pessoas de sexos diferentes dificilmente realizam atividades juntas. A análise desloca o eixo da questão da vulnerabilidade atribuída às mulheres como grupo de risco, para apreender os impeditivos para sua baixa adesão à pratica de atividades esportivas de lazer.

\section{Análise de relatórios de estudos sobre lazer em Porto Alegre e Rio de Janeiro}

Para a construção desse texto, analisamos os relatórios de três pesquisas que examinaram programas de políticas públicas de saúde e lazer, duas realizadas em Porto Alegre e uma na cidade do Rio de Janeiro. O elo entre elas é gênero ter sido eleita como uma das suas categorias analíticas, além é claro, do envolvimento efetivo dos autores nas pesquisas já desenvolvidas ${ }^{9}$.

\footnotetext{
${ }^{7}$ Sobre a emergência do discurso da vida ativa no cenário da promoção da saúde contemporânea e o programa Agita São Paulo sugerimos a leitura de Fraga (2006).

${ }^{8}$ Em pesquisa anterior realizamos o mapeamento em 16 periódicos nacionais vinculados a área da Educação Física e Ciências do Esporte, Educação e Gênero sobre temas relacionados a gênero, etnia, esporte, lazer e educação Física. Foram identificados 216 artigos contemplando essas temáticas. No entanto ao cruzarmos os descritores gênero e lazer foram encontrados apenas seis: Marin (1993), Telles (1996), Mascarenhas (1999), Oliveira (2001), Leiro (2001), Janata (2002).

${ }^{9}$ As pesquisas desenvolvidas nas cidades de Porto Alegre e Rio de Janeiro integram o projeto "Gênero e Etnia: subsídios para a elaboração de políticas públicas no esporte e lazer" financiado pelo Ministério do Esporte. Maiores informações podem ser acessadas no endereço:
} http://www.esef.ufrgs.br/ceme/grecco/generoeetnia/index.html 
Silvana V. Goellner, Sebastião J. Votre, Lazer e Gênero nos Programas de Esporte e Lazer das Cidades Ludmila Mourão e Márcia Luiza M. Figueira

Em Porto Alegre, foram analisados os dados oriundos de pesquisa desenvolvida junto ao "Programa Lazer e Saúde", promovido pela Secretaria Municipal de Esportes, Recreação e Lazer (SME), que orienta caminhadas e assessora os caminhantes, oferecendo os serviços de controle de pressão arterial e freqüência cardíaca. Transcorrido três meses de observação, verificamos que tanto os homens quanto as mulheres participavam das caminhadas na mesma proporção. Desautorizando a literatura, são semelhantes os índices de participação e de motivação para participar, em ambos os sexos. Predominam depoimentos valorizando a saúde e a qualidade de vida como razão para caminhar ${ }^{10}$, conforme podemos perceber nos registros abaixo:

É eu tenho uma amiga, tá, que ela, eu digo olha tu leva uma vida sedentária, tu tem todas as mesmas doenças que eu tenho e tu não procura fazer uma caminhada, ou seja, de 10, 15, 20 minutos que já te ajuda. E ela se queixa muito de dor nos ossos, ela tem diabetes, ela tem osteoporose, tem artrose, tem tendinite, e é uma pessoa sedentária, não faz nada (Entrevistada 5, 60 anos, aposentada).

O questionamento à amiga denota que a informante possui consciência crítica dos malefícios do sedentarismo e dos benefícios da atividade física. Ela se estabelece como exemplo de quem melhorou sua qualidade de vida aderindo à prática sistemática de caminhada.

Ao entrevistarmos um usuário do programa ouvimos o seguinte depoimento:

Pra mim a primeira coisa que vem é a saúde, cara que não pratica esporte, ele é propício a ter algum tipo de doença, diabetes, tanto é que eu tô caminhando por causa da minha diabetes também, né. Eu não caminhava, eu jogava bola depois parei um bom tempo de praticar esporte, aí depois eu vi que tava diabético do tipo II aí comecei a fazer exercício, faz um ano que tô caminhando no parque aí e já melhorou bastante (Entrevistado 3, 48 anos, desempregado).

${ }^{10}$ Outros depoimentos sobre a concepção de sedentarismo e a relação entre atividade física e vida saudável podem ser acessadas em Fraga et al (2009). 
Silvana V. Goellner, Sebastião J. Votre, Lazer e Gênero nos Programas de Esporte e Lazer das Cidades Ludmila Mourão e Márcia Luiza M. Figueira

A exemplo dos dois registros acima, a relação direta entre prática de atividade física e melhoria da saúde emergiu em vários dos discursos dos/as caminhantes, o que nos permitiu inferir a centralidade que esse binômio adquiriu na vida dos depoentes. Parece que se consolidam as representações sobre efeitos positivos da adesão às atividades físicas tanto para homens como para mulheres. Nesse sentido, os colaboradores do estudo, independente de seu sexo, parecem impregnados da crença de que "o sedentarismo é um mal nem sempre visível que está sempre à espreita e a prática de caminhadas ou qualquer outra atividade física uma forma de evitar essa ameaça à saúde" (FRAGA et al, 2009, p. 32).

A segunda pesquisa desenvolvida em Porto Alegre apresentava como principal objetivo verificar como se dava a adesão de homens e mulheres nas práticas corporais desenvolvidas nas atividades oferecidas em cinco núcleos ${ }^{11}$ do Programa Esporte e Lazer da Cidade (PELC), que é gerenciado pela Secretaria Nacional de Desenvolvimento de Esporte e de Lazer do Ministério do Esporte.

O PELC foi elaborado para suprir a carência de políticas públicas e sociais que atendessem às crescentes necessidades e demandas da população em busca de atividades direcionadas para esporte recreativo e o lazer. Sua meta busca democratizar o acesso às práticas esportivas e de lazer e universalizar o direito social ao esporte e ao lazer. Além da prática de atividades físicas e esportivas, propõe outras atividades voltadas para o atendimento de pessoas de diferentes faixas etárias das comunidades nas quais se desenvolve. Nos termos de Bonalume et al. (2008, p. 63), o Programa contempla, desde seu início, o estímulo à “convivência social, à formação de gestores e

11 Estes núcleos estão assim localizados: Associação de Moradores do Loteamento Pampa; Parque Mascarenhas de Moraes (Humaitá); Praça Rejane Vieira (Vila Cruzeiro); Associação dos Amigos da Safira (Vila Safira) e Associação de Amparo aos Necessitados (Vila Bom Jesus). O atendimento ocorre em vários locais das comunidades citadas tais como praças, quadras, associações de bairros, creches e demais locais disponíveis. 
Silvana V. Goellner, Sebastião J. Votre, Lazer e Gênero nos Programas de Esporte e Lazer das Cidades Ludmila Mourão e Márcia Luiza M. Figueira

lideranças comunitárias e à socialização do conhecimento, contribuindo para que o esporte e o lazer sejam assumidos como políticas públicas e de direitos de todos”. Com efeito, as propostas se pautam por uma perspectiva de construção da cidadania, inclusão social e contribuição à redução dos índices de violência através do esporte e lazer.

Os núcleos do projeto localizam-se em comunidades com elevada densidade populacional e altos índices de violência física e psicológica e tráfico de drogas, com um número crescente de crianças e adolescentes em situação de rua, mendicância, além de índices preocupantes de gravidez precoce. A justificativa para a implantação do PELC na cidade de Porto Alegre referia a possibilidade de "contribuir com a prevenção e combate a todos os tipos de violência e exclusão social e, acima de tudo, garantindo o direito constitucional de acesso às práticas de esporte e lazer” (SME, 2007, p. 3).

Nos cinco núcleos ativos na cidade de Porto Alegre no ano de 2008, foram mapeadas todas as atividades oferecidas pelo Programa e foi verificado que cada núcleo desenvolveu atividades apropriadas à cultura local e às demandas e interesses das comunidades, desde voleibol, futsal, futebol de campo, handebol, basquete, capoeira, judô, jiu-jitsu, dança, expressão corporal, alongamento e ginástica, até oficinas de artesanato, de hip-hop, de percussão e grafitagem. Além dessas foram ofertadas atividades de formação de grupos de convivência de adultos e de terceira idade, bem como grupos multiesportivos e brinquedotecas.

Para apreender as questões de gênero que perpassavam o cotidiano desses núcleos passamos a observar de forma sistemática as atividades desenvolvidas. Procedemos também a um sociodiagnóstico das expectativas dos sujeitos a serem contemplados com a implementação do Programa. Os informantes (149 homens e 109 mulheres) responderam a um questionário, composto de três perguntas, com foco na 
Silvana V. Goellner, Sebastião J. Votre, Lazer e Gênero nos Programas de Esporte e Lazer das Cidades Ludmila Mourão e Márcia Luiza M. Figueira

distribuição por gênero: 1) O que você gosta de fazer no seu tempo livre; 2) O que você entende por lazer? e 3) O que impossibilita você a praticar atividade física?

A análise dos dados, realizada mediante a triangulação dos dados advindos de observação sistemática, questionários e referencial teórico confirmou que a preferência das mulheres estava marcada pela realização de atividades no espaço doméstico, enquanto a dos homens se voltava para o espaço público. Mais de 50\% delas afirmaram que não realizam qualquer tipo de atividade física, quer como lazer, quer para cuidar da saúde. Atribuem aos afazeres domésticos o principal fator que as impede de ter uma atividade física regular, pois dadas as demandas que essa tarefa exige, não sobra tempo para cuidarem de si mesmas. Já a maior parte dos homens mencionou a prática do futebol como atividade para ocuparem seu tempo livre. Somente a quarta parte dos homens diz não realizar atividades físicas regularmente, tendo como principais razões a doença e a falta de tempo relacionada as demandas do trabalho.

\section{Discussão dos resultados de Porto Alegre}

Esses dados da cidade de Porto Alegre, quando analisados com referência ao gênero, podem ser lidos sob diferentes perspectivas, a começar pela divisão social do trabalho: as mulheres, em sua imensa maioria, são as responsáveis pelos cuidados da casa e da família. O estudo de Gross (2008) aponta que a maior categoria de profissionais no nosso país é formada por mulheres e que grande parte delas ainda não tem acesso aos direitos trabalhistas, o que se deve, entre outros fatores, à relação que se estabelece entre trabalho remunerado e não remunerado. Para a autora,

Os homens se ocupam, majoritariamente, de um trabalho considerado produtivo, que tem mensuração, que você pode valorar, ou seja, pelo produto produzido ou pela mão-de-obra empregada para realizá-lo. Às 
Silvana V. Goellner, Sebastião J. Votre, Lazer e Gênero nos Programas de Esporte e Lazer das Cidades Ludmila Mourão e Márcia Luiza M. Figueira

mulheres lhes compete o trabalho considerado reprodutivo, o que significa a manutenção da perpetuação da espécie humana, o cuidado cotidiano com as pessoas com as quais elas convivem, que estão ao seu redor, como seus filhos e filhas, pessoas mais idosas, as pessoas com deficiência e doentes, para as quais elas têm que preparar alimentação, se responsabilizar pela vestimenta, organizar o lugar onde o núcleo familiar vive (GROSS, 2008, p. 240).

Essa distribuição de tarefas interfere diretamente no acesso ao lazer. Com efeito, em sua grande maioria as mulheres adultas entrevistadas afirmaram que seu lazer estava voltado para atividades realizadas com a própria família, dentro do espaço doméstico. Quando questionadas sobre o que entendiam por tempo livre, quase todas responderam que não têm tempo livre e quando pensam em lazer pensam em descanso, em assistir televisão, em conversar, tomar chimarrão ou dormir. Algumas das respostas à pergunta "O que você gosta de fazer no seu tempo livre?" mostram a relação que as mulheres estabelecem com o trabalho e com o lazer, pois as tarefas domésticas "mais leves" são apresentadas como lazer. Dentre essas, destacamos: limpar a casa e olhar TV; cuidar da filho pequeno; ficar deitada e levar filhos para passear.

Entre os impedimentos elas destacam a falta de tempo, por conta do trabalho fora de casa e/ou dos cuidados com a casa, a família e em especial os filhos. As respostas sobre o que é lazer, das mulheres que têm algum tempo livre, privilegiam o descanso: ter um monte de descanso; a casa onde mora; não fazer nada; descanso para a memória. Obtivemos apenas duas falas sobre lazer ativo: ficar tranqüila fazendo o que eu gosto, sem me preocupar com horários; poder fazer coisas que eu gosto. ${ }^{12}$

12 Esses resultados coincidem com os da Fundação Perseu Abramo, em pesquisa de 2001, com 2502 mulheres em todas as regiões do país. As respostas para atividades realizadas nas horas de lazer, nos finais de semana ou no tempo livre, apontaram que $63 \%$ têm o lazer voltado para as atividades domésticas: assistir televisão, dormir, fazer trabalhos manuais, descansar, conversar com as vizinhas, cuidar de plantas ou horta, ficar com a família, ficar na porta da casa olhando o movimento da rua. (VENTURI, RACAMÁN e OLIVEIRA, 2004). 
Silvana V. Goellner, Sebastião J. Votre, Lazer e Gênero nos Programas de Esporte e Lazer das Cidades Ludmila Mourão e Márcia Luiza M. Figueira

Para os homens da amostra, lazer é sinônimo de diversão, de algo que está fora da rotina: beber com os amigos, assistir/ouvir futebol. Dos 149 homens que responderam o questionário, predomina a preferência pelo futebol, poucos dizem não realizar algum tipo de atividade física, em razão de doença ou de falta de interesse, já que não apresentam qualquer impedimento. Eles não referem as atividades familiares como parte de sua rotina de trabalho e, muito menos, de lazer. Seu lazer está vinculado à ação: “é divertir-se, realizando algum esporte"; "é se divertir e melhorar a sua saúde"; "é um meio de diversão a todos, especialmente uma caminhada". Identificamos apenas uma resposta ligada ao lar: "é tranqüilidade de viver e um espaço saudável para as crianças" (Entrevistado 21, 34 anos, motoboy).

Até agora falamos sobre informantes adultos. No segmento dos entrevistados, com idade inferior a 14 anos, a compreensão de lazer, para meninos e meninas, é similar à do segmento adulto masculino. Para meninos e meninas, lazer relaciona-se à diversão e à prática de esportes. Poucas meninas preferem atividades comumente designadas como mais próprias aos meninos, tais como futebol, capoeira e jiu-jitsu e reivindicam tal oportunidade.

A preferência e a reivindicação feminina indiciam e denunciam a presença de distinções da ordem do gênero nas atividades, tanto as realizadas no PELC quanto as imaginadas. Um dos pontos positivos por nós avaliados foi a presença, nos núcleos, de esforços para realização de atividades conjuntas entre meninos e meninas bem como a efetiva participação de meninas e moças em atividades como futebol e lutas. 
Silvana V. Goellner, Sebastião J. Votre, Lazer e Gênero nos Programas de Esporte e Lazer das Cidades Ludmila Mourão e Márcia Luiza M. Figueira

\section{Análise de relatórios de estudos sobre lazer e gênero no Rio de Janeiro}

Na cidade do Rio de Janeiro, o Programa de Esporte e Lazer na Cidade, tanto quanto um dos estudos desenvolvidos em Porto Alegre, teve por objetivo realizar um sociodiagnóstico com atenção especial para a variável gênero, a fim de verificar se o sexismo contribuía para a ausência dos usuários e das usuárias nas atividades desenvolvidas nos seus núcleos.

Os dados deste estudo foram provenientes de registros em diário de campo, onde anotávamos comportamentos e falas relevantes. Nessas falas despontavam aqueles/as que demonstravam liderança, e eram em seguida entrevistados/as individualmente, representando invariavelmente, o grupo que freqüentava o projeto há mais tempo. No grupo focal (GATTI, 2005), outra técnica utilizada, conversas eram provocadas com grupos de usuários/as ao final das atividades praticadas, a partir de questões como, por exemplo, "Vocês sabem o porquê da grande quantidade de mulheres nesta atividade?", “Por que seu esposo/esposa não participa das atividades?". "Vocês gostam de jogar com as/os meninas/os?" Enfim, conversávamos sobre razões das dificuldades e facilidades de participação nas atividades pelos usuários/as, nas 12 comunidades pesquisadas onde atua o PELC. ${ }^{13}$ Desta forma a técnica da triangulação conjugou as fontes empíricas advindas do diário de campo, do grupo focal e das entrevistas.

A cidade do Rio de Janeiro possui 20 núcleos do PELC, e após visita, adotamos como critério de inclusão a redundância nas respostas às perguntas das entrevistas. Desta feita, vamos nos referir aos núcleos como se fossem apenas um, na medida em que se repetiram os depoimentos dos/das usuários/as no tocante ao gênero.

${ }^{13}$ As comunidades investigadas foram as seguintes: Rocha Miranda, Vila Aliança, Vila Kennedy, Jabour, Senador Camará, Vidigal, Horto, Penha, Bangu, Cidade Nova, Mineira e Jardim América, comunidades estas localizadas em áreas de vulnerabilidade social e econômica. 
Silvana V. Goellner, Sebastião J. Votre, Lazer e Gênero nos Programas de Esporte e Lazer das Cidades Ludmila Mourão e Márcia Luiza M. Figueira

Assim como na cidade de Porto Alegre, no Rio de Janeiro as atividades oferecidas variam, de acordo com a disponibilidade de espaços adequados nas comunidades e de interesses de algumas dessas comunidades. Algumas atividades predominam na maioria dos núcleos, a exemplo da ginástica, vôlei e futebol. Há atividades que só são oferecidas em um ou dois núcleos, a exemplo de alongamento, artesanato, dança do ventre, tênis de mesa, pimbolim e musculação.

A maioria das mulheres pratica a ginástica nos diferentes núcleos; esta escolha aparece como traço identitário feminino na atividade física nos espaços públicos de lazer e acompanha os resultados encontrados no estudo de Neiva e Mourão (2009) acerca das representações de atividade física de mulheres na cidade do Rio de Janeiro. Nesta perspectiva o segmento feminino parece não ter o costume de se exercitar da mesma forma que os homens.

Outra pesquisa que direcionou seu olhar para o mundo das práticas culturais de lazer desenvolvidas por um coletivo de mulheres das camadas populares da cidade de Diadema (SP), foi a de Cavaleiro (2005), que verificou que as "as mulheres demandavam atividades de ginástica como uma possibilidade de ação preventiva ou curativa no campo da saúde, além da disputa pelo direito à ocupação do tempo disponível” (p.02). O estudo sinaliza a situação de mulheres reivindicando seus espaços, fazendo suas escolhas, mas também aponta a presença do discurso que promove a atividade física como vetor de saúde. Podemos assumir que a melhora da aptidão e da forma física e a busca da sensação de bem estar são aspectos relevantes no processo decisório dos indivíduos ao se engajarem em programas regulares de atividades físicas. Estas buscas são interpretadas como fatores altamente motivadores para que os indivíduos empreendam esforços no sentido de adotar um comportamento mais ativo e 
Silvana V. Goellner, Sebastião J. Votre, Lazer e Gênero nos Programas de Esporte e Lazer das Cidades Ludmila Mourão e Márcia Luiza M. Figueira

os espaços mais adequados no alcance destes objetivos são aqueles organizados pelas políticas públicas, sobretudo para as classes populares.

O sociodiagnóstico revelou que nos núcleos em que não se levam em conta os interesses específicos dos/as usuários/as há um índice alto de evasão nas atividades oferecidas. O que nos leva a crer que as políticas públicas deveriam orientar-se por sociodiagnóstico que revelassem os interesses e anseios das comunidades, assim como suas característica sociodemográficas.

\section{Discussão dos resultados do Rio de Janeiro}

A vergonha e o interesse pessoal e de grupos etários pelas atividades físicas, foram categorias observadas que motivaram atitudes e ações preconceituosas e discriminatórias de gênero, demarcando as atividades que seriam freqüentadas por usuários de sexo distinto. Não encontramos atividades que fossem praticadas de forma conjunta por homens e mulheres e meninos e meninas. Os homens raramente comparecem em atividades em que predominam as mulheres, assim como mulheres na sua grande maioria não freqüentam atividades em que predominam os homens. No curso da história, homens e mulheres foram educados praticando exercícios diferentes; o que era aconselhado para os homens não correspondia ao que as mulheres deveriam realizar. Esta separação, baseada na biologia dos corpos, terminou por en gendrar-se na cultura brasileira determinando o que é masculino e o que é feminino em termos de atividades físico-esportivas. A partir destas considerações, e mesmo na atualidade em que já presenciamos a igualdade entre os sexos na maioria das atividades, nas atividades físico-esportivas ainda é comum encontrarmos homens e mulheres e meninos e meninas em mundos separados, independentemente da classe social. 
Silvana V. Goellner, Sebastião J. Votre, Lazer e Gênero nos Programas de Esporte e Lazer das Cidades Ludmila Mourão e Márcia Luiza M. Figueira

Algumas situações foram identificadas nos núcleos, mais especificamente, relacionadas ao futebol e à ginástica que exemplificam o contexto encontrado: Uma garota disse que "só vai ao futebol se uma amiga for junto, tem vergonha porque os meninos vão ficar olhando, se fosse em um lugar fechado, e só com mulher, seria melhor”. (Idade, 15 anos). Essa fala indica, grosso modo, que muitas meninas sentem vergonha de serem observadas pelos meninos no futebol, sobretudo pela falta de habilidade para o jogo.

Identificamos também a fala de um professor cujo depoimento relatou que "muitas garotas já lhe perguntaram se poderiam jogar, ele sempre diz que sim, mas ao verem grande quantidade de homens jogando elas desistem e dizem: "ah não, vão me machucar, eles chutam muito forte" (Idade, 24 anos).

Esse parece ser o sentimento expresso pelos meninos que em seus depoimentos, por sua vez, dizem que "não gostam de jogar com as meninas, por elas serem pernas de pau”. (Grupo focal, 06 meninos). No futebol, a predominância absoluta é de homens; há apenas um núcleo em que o número de mulheres praticando é significativo. Nesse caso, ao serem perguntados se gostam de jogar com elas, os rapazes disseram que não há problema algum. $\mathrm{O}$ mesmo disseram as meninas (grupo focal, 5 meninas). Mas ao serem perguntados se preferem uma turma só deles, ou só delas, a resposta aponta que seria bem melhor

Observa-se que homens e mulheres apresentam comportamentos diferentes na prática de atividades físicas no lazer esportivo. Salles-Costa et al (2003), ao estudar adultos de uma determinada instituição e suas opções de lazer, observaram que os esportes mais praticados por homens estão caracterizados como sendo coletivos e de uso da força muscular, enquanto que os esportes mais praticados pelas mulheres se 
Silvana V. Goellner, Sebastião J. Votre, Lazer e Gênero nos Programas de Esporte e Lazer das Cidades Ludmila Mourão e Márcia Luiza M. Figueira

caracterizam por serem individuais e ligados com o objetivo de controle da imagem corporal. Este dado da nossa cultura pode ser observado, de uma forma geral, em todos os ambientes esportivos e neles, as atividades com características de uso da força são em geral as lutas, a musculação e os diversos esportes coletivos de confronto. ${ }^{14}$

Essas narrativas reafirmam a representação recorrente em vários espaços sócioesportivos, onde o futebol é uma modalidade mais apropriada aos homens do que as mulheres. Razão pela qual são quase naturalizadas as manifestações dos/das usuários/as, conforme observamos e por assim serem, não são problematizadas com o intuito de modificar essa situação objetivando agregar mais mulheres à esta prática.

Já nas atividades de alongamento e ginástica, onde as mulheres são absolutas, as senhoras disseram que "eles não vêm porque têm vergonha, tem muita mulher" (Grupo focal, 12 mulheres). Segundo essas mulheres, muitos homens não participam da atividade porque trabalham e, quando essa acontece muito cedo dizem eles é porque preferem ficar dormindo, são as formas de negar as atividades que fogem ao seu interesse.

Após conversarmos com um grupo de mulheres que lamentavam que seus maridos não participassem de atividades que elas consideram importantes para eles,

14 Eric Dunning (1992) define "desportos de confronto" como aqueles que "constituem áreas privilegiadas para uma expressão socialmente aceitável, ritualizada e mais ou menos controlada de violência física (p. 393). A partir de dados britânicos do século XIX, o autor sugere que os clubes onde se praticavam estes esportes seriam exemplo de locais criados e controlados pelos homens para garantir um espaço em que pudessem exercer sua expressão de masculinidade e de forma simbólica "imitar, reificar e caluniar as mulheres, que então, mais do que nunca, representavam uma ameaça ao seu estatuto e a imagem que tinham de si próprios" (p. 410). A tradição desses esportes traz consigo a marca de uma atividade criada e praticada por homens, e também, com características inerentes de agressividade, força, competitividade e de estratégias em grupo para o seu melhor desempenho. 
Silvana V. Goellner, Sebastião J. Votre, Lazer e Gênero nos Programas de Esporte e Lazer das Cidades Ludmila Mourão e Márcia Luiza M. Figueira

entrevistamos um senhor que, apesar de não freqüentar essas atividades gostaria de fazê-lo, segundo depoimento de seus amigos. Ao ser perguntado sobre o motivo da sua ausência, após pensar um pouco, ele disse que provavelmente é por "vergonha do que os outros homens vão dizer ao me verem fazendo atividades com mulheres" (Idade, 70 anos).

Em outro caso, durante uma aula de dança de salão com predominância de mulheres, um dos poucos homens presentes disse sofrer preconceito dos amigos, "eles falam que dança de salão é coisa de mulherzinha, boiolinha" (Idade, 65 anos).

Em situações como estas observamos, ainda, o quanto a identidade de gênero acaba por ser atravessada pela identidade sexual. Ou seja, o fato de um homem participar de uma atividade identificada na cultura como feminina, dá margem a que sua orientação sexual seja colocada em suspeição, independentemente da idade.

Ao observarmos as aulas de capoeira, freqüentada por um usuário do PELC que se identificou como do sexo feminino, adotando inclusive nome de uma famosa mulher, percebemos que ele se posiciona no fundo da sala e é ignorado pela professora. Quando entrevistado afirma que "só faço esta aula, pra poder me defender dos ataques na rua e em casa do irmão" (Idade, 30 anos).

Ainda no que diz respeito a identidade sexual, apontamos o relato de uma garota que se destaca no futsal por ter muita habilidade com a bola, e é freqüentemente chamada de sapatona ${ }^{15}$, o que ela odeia. Ao se sentir desconfortável mediante o apelido, deixou de ir ao núcleo, evidenciando o quanto o preconceito pode se constituir em um fator de evasão.

15 Termo pejorativamente atribuído à mulher lésbica. Sua utilização, neste caso, evidencia o quanto a escolha por uma modalidade esportiva culturalmente designada como considerada "masculina" invoca, de imediato, a suspeição sobre a orientação sexual da praticante. 
Silvana V. Goellner, Sebastião J. Votre, Lazer e Gênero nos Programas de Esporte e Lazer das Cidades Ludmila Mourão e Márcia Luiza M. Figueira

Além dessas questões identificamos, ainda, que o grau de habilidade motora, por vezes associada a gênero, também contribui para a ausência e evasão das pessoas em algumas atividades desenvolvidas nos núcleos. Em um deles verificamos que as aulas de voleibol estão voltadas para usuários/as que já possuem certa habilidade, caracterizando-se quase como uma atividade de treinamento da modalidade. Segundo os próprios usuários desta turma, este fato contribui para o afastamento de interessados menos habilidosos. O professor justifica dizendo que "é muito difícil mesclar turmas de voleibol quando os meninos possuem habilidades e força física maior que as meninas" (Idade, 25 anos).

Vários relatos e observações dão conta da presença de homens, em atividades de lazer, próximo ao local de atividades esportivas do PELC. Eles estão sempre jogando cartas ou sinuca. Quando perguntados sobre por que não participam das atividades do PELC, respondem que preferem atividades mais intensas, como corridas e caminhadas. Em termos gerais, podemos dizer que os homens rejeitam as atividades do PELC por considerá-las mais voltadas ao público juvenil e/ou feminino.

O preconceito de gênero provém também dos pais dos participantes, como no caso da mãe que não deixa sua filha jogar futebol: "vai fazer o que lá, futebol é coisa de homem". (Idade, 40 anos). Ou da mãe que não deixa a filha participar do festival de pipas, por lá predominar meninos. (Idade, 35 anos)

\section{Conclusão}

A análise das bases de dados das pesquisas desenvolvidas nas cidades de Porto Alegre e do Rio de Janeiro levou-nos a constatar que há diferença de oportunidades entre homens e mulheres para se dedicarem às atividades de lazer, enquanto as mulheres 
Silvana V. Goellner, Sebastião J. Votre, Lazer e Gênero nos Programas de Esporte e Lazer das Cidades Ludmila Mourão e Márcia Luiza M. Figueira

têm sua vida atrelada à casa, à família e ao trabalho, os homens depois do trabalho se dedicam ao lazer. A análise mostrou, também, que em relação as políticas públicas há um desafio de aproximar interesses de homens e mulheres nas atividades de lazer ativo, bem como de criação de estratégias para a ampliação da participação das mulheres em atividades de lazer.

Os depoimentos confirmam que o espaço de lazer é generificado e generificador, pois nele produzem-se e reproduzem-se comportamentos, ações, discursos e práticas diferenciadas para homens e mulheres, que reafirmam representações hegemônicas de masculinidades e feminilidades.

Os estudos aqui analisados apontam para a necessidade de gestores se prepararem para lidar com as questões de gênero e estarem atentos aos riscos da generificação, no momento da elaboração de políticas e projetos de atividades físicoesportivas e de lazer, pois esse marcador identitário interfere na adesão e permanência de homens e mulheres de formas distintas e desiguais. Por certo outros fatores também reforçam estas e outras desigualdades. No entanto, não podemos negar que as relações de gênero configuram espaços diferenciados para eles e para elas. Trata-se de uma questão política que, como tal, merece ser amplamente discutida e referenciada.

\section{REFERÊNCIAS}

BONALUME, C. R. et al. O Programa Esporte e Lazer na Cidade. In: PINTO, L. M. S. de M. et al. (org.). Brincar, Jogar e Viver: lazer e intersetorialidade com o PELC. Brasília: Ministério do Esporte, 2008. v.1, n. 1, p. 61-67. 
Silvana V. Goellner, Sebastião J. Votre, Lazer e Gênero nos Programas de Esporte e Lazer das Cidades Ludmila Mourão e Márcia Luiza M. Figueira

CAVALEIRO, M. C. "Mulheres em Movimento": lazer e educação no espaço urbano. REUNIÃO ANUAL DA ANPED, 28, 2005, Caxambu. Anais... Disponível em: <http://189.1.169.50/reunioes/28/gt03.htm >. Acesso em: 23 jan. 2008.

DUNNING, E. O desporto como uma área masculina reservada: notas sobre os fundamentos sociais da identidade masculina e as suas transformações. In: ELIAS, N. A busca da excitação. Lisboa: DIFEL, 1992.

FRAGA, A. B. Exercício da Informação: governo dos corpos no mercado da vida ativa. Campinas: Autores Associados, 2006.

FRAGA, A. B. et al. "Sedentarismo é...": concepções de praticantes de caminhada e a medicalização das práticas corporais. In: FRAGA, A. B. et al (Org.). Políticas de lazer e saúde em espaços urbanos. Porto Alegre: Gênese, 2009.

GATTI, B. A. Grupo focal na pesquisa em ciências sociais e humanas. Brasília: Líber Livro, 2005.

GOELLNER. S. V. et al. Gênero e Raça: inclusão no esporte e lazer. Porto Alegre: Ministério do Esporte/Gráfica da UFRGS, 2009.

GROSS, D. M. Estratégias para o desenvolvimento de políticas públicas intersetoriais: perspectivas de parceria com o lazer. In: PINTO, L. M. S. de M. et al. (org.). Brincar, Jogar e Viver: lazer e intersetorialidade com o PELC. Brasília: Ministério do esporte, 2008. v. 1, n. 1, p. 238-247.

INSTITUTO BRASILEIRO DE GEOGRAFIA E ESTATÍSTICA. Censo Demográfico 2000. Rio de Janeiro: IBGE, 2000.

JANATA, N. E. O trabalho e o lazer/lúdico das meninas-jovens de assentamentos do MST. Motrivivência, Florianópolis, v.13, n. 19, p. 01-16, jul/dez. 2002.

LEIRO, A. C. R. Políticas Públicas e relações de gênero no âmbito do lazer. Revista Brasileira de Ciências do Esporte, v. 21, n. 1, 2001, p. 229-249.

MARIN, E. C. Lazer da mulher camponesa: do vivido ao aspirado. Revista Brasileira de Ciências do Esporte, Campinas, v. 15, n. 1, p. 65-74, set/dez. 1993.

MASCARENHAS, F. Meninos e meninas em situação de rua: à guisa de um Baculejo, Revista de Educação Física, Maringá, v. 10, n. 1, p. 33-46, set.1999.

NEIVA, G. MOURÃO, L. As representações sociais de atividade física de mulheres freqüentadoras de academias de ginástica: entre a necessidade e o gosto. Rio de Janeiro, 2009. Mimeografado.

OLIVEIRA, S. R. de. A relação das mulheres que fazem parte da população economicamente ativa, casadas, que têm filhos, com o lazer. Revista Brasileira de Ciências do Esporte, Campinas, v. 21, n. 1, p. 152-163. set/dez. 2001. 
Silvana V. Goellner, Sebastião J. Votre, Lazer e Gênero nos Programas de Esporte e Lazer das Cidades Ludmila Mourão e Márcia Luiza M. Figueira

SALLES-COSTA, R. et al. Associação entre fatores sócio-demográficos e prática de atividade física de lazer no estudo pró-saúde. Cadernos de Saúde Pública, São Paulo, v. 19, n. 4, p.1095-1105, jul./ago. 2003.

SECRETARIA MUNICIPAL DE EDUCAÇÃO DE PORTO ALEGRE. Programa Esporte e Lazer Da Cidade: Projeto Básico - 2007/2008. Renovação do Convênio e Implantação de Núcleos de Esporte e Lazer, 2007. Mimeografado.

TELES A. A freqüência aos parques de lazer na cidade do Recife: o perfil de seus frequentadores. Motus Corporis, Rio de Janeiro, v. 1, n. 1, p. 43-48, jul/nov. 1996.

VENTURI, G.; RECAMÁN, M.; OLIVEIRA, S. A mulher brasileira nos espaços público e privado. São Paulo: Editora Fundação Perseu Abramo, 2004.

\section{Endereço dos Autores:}

Silvana Vilodre Goellner

Escola de Educação Física (UFRGS)

Rua Felizardo, 750

Jardim Botânico - Porto Alegre - 90690-200

Endereço Eletrônico: goellner@terra.com.br 